\title{
DÜBLIN
}

Technological University Dublin ARROW@TU Dublin

\section{UAV data for coastal dune mapping}

\author{
Chen Suo \\ Technological University Dublin \\ Eugene McGovern \\ Technological University Dublin, eugene.mcgovern@tudublin.ie \\ Alan Gilmer \\ Technological University Dublin, alan.gilmer@tudublin.ie
}

Follow this and additional works at: https://arrow.tudublin.ie/ehsicon

Part of the Civil and Environmental Engineering Commons, and the Environmental Sciences Commons

\section{Recommended Citation}

Suo, Chen \& Mcgovern, Eugene \& Gilmer, Alan. (2017). UAV Data for Coastal Dune Mapping. 10.3846/ enviro.2017.245.

This Conference Paper is brought to you for free and open access by the ESHI Publications at ARROW@TU Dublin. It has been accepted for inclusion in Conference papers by an authorized administrator of ARROW@TU Dublin. For more information, please contact arrow.admin@tudublin.ie, aisling.coyne@tudublin.ie, gerard.connolly@tudublin.ie.

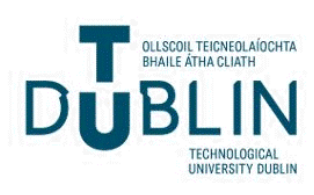




\title{
UAV Data for Coastal Dune Mapping
}

\author{
Chen $\mathrm{Suo}^{1}$, Eugene McGovern², Alan Gilmer ${ }^{3}$ \\ Environmental Sustainability \& Health Institute, Dublin Institute Technology, Dublin, Ireland \\ E-mails: ${ }^{1}$ 15123973@mydit.ie; ${ }^{2}$ eugene.mcgovern@dit.ie; ${ }^{3}$ alan.gilmer@dit.ie
}

\begin{abstract}
High resolution topographic maps are critical for the development of rigorous and quantitative numerical simulation landscape models. These models can inform targeted land management actions that maintain biodiversity and ecological functions. Mapping functional vegetation communities to obtain accurate distribution and population estimates is an important element of landscape models and is a challenging task which requires a considerable investment in time and resources. A recent development in surveying technologies, Unmanned Aerial Vehicles (UAV's), also known as drones, has enabled high resolution and high accuracy ground-based data to be gathered quickly and easily on-site. The application of UAV's represents a new opportunity to survey relatively large areas in significantly less time compared to other on-site surveying methods, including GPS, robotic total stations and terrestrial laser scanners. The objective of this research is to use UAV technology to create topographical and vegetation mapping of coastal dune complexes with particular reference to the Brittas-Buckroney dune complex in Co. Wicklow. As the area of study site was about 60 hectares, it was divided into three sections, North, Centre and South. This paper presents the five steps to achieve the objective, setting ground control points, making an autonomous flight plan, flying the UAV for data collection, data processing and result analysis via ArcGIS. The final result, processed by specific software PIX4D, was a topographical map of the study site in the Irish Transverse Mercator coordinate system, with a resolution of $0.125 \mathrm{~m}$ and Root-Mean-Square (RMS) error $0.050 \mathrm{~m}$. In conclusion, UAV technology provides new possibilities for mapping as it maximizes improvement of the data quality while reducing the investment in time and labour.
\end{abstract}

Keywords: coastal dune complexes, unmanned aerial vehicles, topographic maps.

Conference topic: Technologies of geodesy and cadastre.

\section{Introduction}

The coastal zone area is important at both the natural and the economic level. The coastal dune field is at the transition between the terrestrial and marine ecosystems which are highly-valued, natural resources for providing drinking water, mineral resources, recreation, eco-services and desirable land for housing development. These natural resources provide food and habitation for aquatic and terrestrial organisms and offer human settlement and recreation spaces as well. Activities at the coastal zone area can contribute to local and national economy development, in areas like aquaculture, fisheries and tourism, and the area also has an important function to control erosion and flooding thus protecting and maintaining environmental development. In recent years, increasing tourism and development in the coastal dune area of the South East of Ireland have resulted in increased pressure on the environment, resulting in issues including soil erosion, flooding and habitat loss.

High-resolution mapping of the topography and the vegetation communities across a dune field, in particular the mixture of different functional plant types such as pioneer versus succession species, is critical for the establishment of rigorous and quantitative numerical simulation landscape models. These models can inform targeted land management actions that maintain biodiversity and ecological functions. However, mapping functional vegetation communities to obtain accurate distribution and population estimates is a challenging task which requires a considerable investment in time and resources.

There are a number of sources of spatial data available for coastal dunes mapping. Satellite imagery provides remotely-sensed panchromatic, spectral and multispectral data, provided by national mapping agencies (NMA's), like Ordnance Survey Ireland (OSI) or the United States Geological Survey (USGS). NMA's can provide base topographical mapping from aerial photography with different ranges of resolutions. From USGS Earth Explorer, a base topographical map is available to download free with the resolution about $30 \mathrm{~m}$. Higher resolution aerial topography maps can be bought from these NMA's or commercial companies. Although valuable, these data may not provide the resolution necessary for accurate numerical modelling of a dune complex. Recently, Digital Elevation Models with a higher resolution from airborne laser scanning have been used for mapping. The airborne laser scanner can collect the database as point clouds and then use them to generate different kind of digital surface model, including 3D maps. A major limitation for this data source is that the cost for airborne laser scanner is quite high and the study site may not have been included in the areas covered by the NMA. Recent developments in surveying technology have enabled high resolution and high accuracy spatial data to be gathered on-site. These technologies include Total Station, robotic Total Stations and RTK GPS where coordinate positions of points are collected and then used to generate 2D maps based on

(C) 2017 Chen Suo, Eugene McGovern, Alan Gilmer. Published by VGTU Press. This is an open-access article distributed under the terms of the Creative Commons Attribution (CC BY-NC 4.0) License, which permits unrestricted use, distribution, and reproduction in any medium, provided the original author and source are credited. 
the features at the collected points. This kind of 2D map has high accuracy and gives a clear representation about the position of particular land features. However, data collection by these technologies is time consuming and therefore may not be suitable for a relatively large study site with various land features. With significant progress in survey technologies, terrestrial laser scanners offer an option to collect point cloud data on-site from which to generate 3D models that accurately show elevation changes of a coastal dune complex.

Most recently, Unmanned Aerial Vehicles (UAV's), variously referred as UAS (Unmanned Aerial Systems), RPAS (Remotely-Piloted Aerial Systems), "Aerial Robots" or simply “drones" (Turner et al. 2016), have enabled high quality ground-based data to be gathered quickly and easily on-site. Most importantly, it is the evolution of technology for the transformation from imagery to point clouds to create digital surface model, including $3 \mathrm{~d}$ map as well. The application of UAV's represents a new opportunity to survey relatively large areas in significantly less time compared to other on-site surveying methods. This paper presents the methodology and efficacy of using UAV's for ground data collection to create topographical and mapping of coastal dune complexes with particular reference to the BrittasBuckroney dune complex in Co. Wicklow, Ireland.

\section{Methodology}

\section{Brief overview of UAV technology}

In recent decades, large-scale decades, photogrammetry was the primary method for the establishment of topographic maps and was widely used in traditional geologic field studies. UAV technology implemented in mapping reflect the evolution of methodology in photo-based 3D reconstruction, making a new possibility for photogrammetry to create 3D maps (Zelizn 2016). Mapping by UAV is also a user-friendly and scalable methodology with the requirement of the specialized software and restrictive image collection conditions. By the great progress in digital camera technology, a larger number of photos with better image quality can be collected in a short time in the field. UAV, integrated with modern digital camera technology, breaks the time and space constraint, allowing a study site to be remotely surveyed in a significantly reduced time with the result of a large number of high resolution and high accuracy images. In the camera model, it represents a $3 \mathrm{D}$ real world as a $2 \mathrm{D}$ image. Structure from Motion (SfM) is a technique that has emerged in the last decade to construct the photogrammetry-based three-dimensional model, creating 3D surface models from a large number of overlapping photographs. SfM was developed in the 1990's in the computer vision industry,

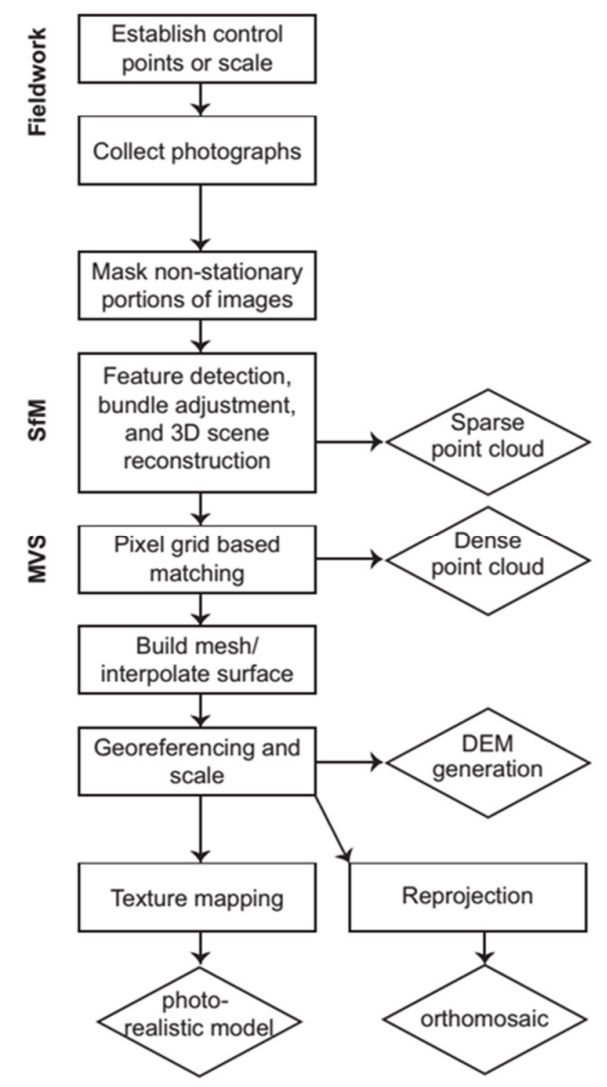

Fig. 1. Photogrammetry-based 3D construction workflow of UAV technology (Bemis et al. 2014) 
impressive by its advances in both motion perception and automated feature-matching algorithms (Lowe 1999). SfM is effective if there is a high degree of overlap that captures the study area from a wide number of different positions and orientations. To generate the topographic map, many thousands of matching object and textural features are automatically detected in multiple overlapping images of the ground surface, from which a high density point cloud with $3 \mathrm{D}$ coordinate positions is derived. The critical element for implementation of photogrammetry to $3 \mathrm{D}$ maps is collection of numerous overlapping images (Uysal et al. 2015). From each two overlapping pictures, specialized software using SfM can calculate the unique coordinate position ( $\mathrm{x}, \mathrm{y}, \mathrm{z}$ or Northing, Easting, Elevation) of a set of particular points presented in both images. To maintain the accuracy of the map, the overlapping area for each two images should be at least $60 \%$, making sure enough shared points can be recognised by software for the map construction. 3D models can be generate by numerous overlapping images without user intervention. But in this way, the 3D models will be in an arbitrary coordinate system. In order to reference the 3D surface model to a real-world system, control points are used to transform all the points in the study area into the correct coordinate system (Tonkin, Midgley 2016). A minimum of three control points needs to be set at the maximum distance over all the study site. The coordinate position of these control points should be obtained and saved as reference for adjusting the whole study site to the correct coordinate system. UAV flight height and speed influence the resolution of collected imagery and are essential to be set in the flight plan to achieve the particular resolution requirement.

In field work, the first thing is to set a certain number of control points depending on the area of the study site. Then total station or Real Time Kinematic GPS technology is used to get the coordinate position of the control points. After this, UAV flight path, including flight height, overlapping percentage and flight speed should be set according to the resolution requirement of the map and then the flight can be started to collect images (Smith et al. 2009). The collected images need to be processed by specialized software, for example Pix4D or Agisoft, which offers a powerful approach to conduct an accurate survey. Importing a wide variety of suitable imagery and control data to the software, a georeferenced 3D model can be effectively constructed. Figure 1 shows the workflow for photogrammetry-based 3D construction.

\section{Irish Aviation Authority for $U A V$}

With the increasing use of UAV in Ireland, over 6,000 drones and model aircraft have been registered with the IAA in the past year. For the management of UAVs in Ireland, the Irish Aviation Authority (IAA) has a mandatory requirement for all owners to register drones weighing $1 \mathrm{~kg}$ or more to be involved in quality training on how to use the UAV properly. IAA also insists that users be aware of their responsibility and operate their UAV in a safe manner and in full compliance with the regulations. The primary emphasis is that the UAV cannot cause harm to people or property, or interfere with other forms of aviation. Moreover, UAV cannot fly over $120 \mathrm{~m}$ above ground level and should be within $300 \mathrm{~m}$ distance from the operator at all times. Before using the UAV, the operator should get the permission from the landowner for take-off and landing. IAA also has strict legislation to prohibit users to operate UAV's over an assembly of people or over urban area or in restricted areas (e.g. military installations, prisons, airport etc.). The authority may define areas within Air Traffic Services airspace, where small unmanned aircraft activity may take place without permission from the Authority. OpenAIP (www.openair.net) is a Worldwide aviation database to deliver free, current and precise navigational data about airports, airspaces, navigational aids, thermal hotspots and many other datasets. In order to fly UAV in a safe location, openAIP can be downloaded free of charge for private use to provide useful information about whether the survey area is in a restricted area. More information on the safe regulation of UAV's in Ireland can be found on the website (www.iaa.ie/drones) and UAV registration is accessible via the website also.

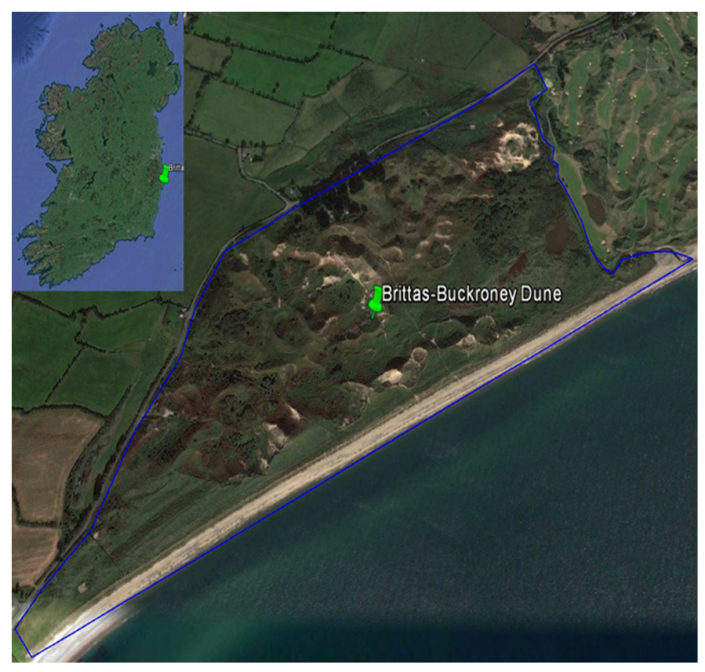

Fig. 2. Study site location map based on Google Earth 


\section{Generating 3D maps of the study site}

Brittas-Buckroney Dunes, located about $10 \mathrm{~km}$ south of Wicklow town in Ireland (Fig. 2), comprises by two main sand dune systems, Brittas Bay and Buckroney Dunes, which are separted by the rocky headland of Mizen Head. The dunes have cut off the outflow of a small river at Mizen Head and a fen, Buckroney Fen, has developed on the site. Ten habitats listed on the EU Habitats Directive, including two priority habitats, occur within the study area. More background information as well as a detailed land cover map of this area are required to highlight the landscape features.

In consideration of maintenance of the high quality of the surveyed data, and the 20-25 min battery life for a single flight of the fixed wing UAV (eBee), the whole study site about 60 hectares was divided into three sections, North, Centre and South. Over 10 control points were chosen in each section and the coordinate position of each was recorded by RTK GPS. For the whole study site, there are 32 ground control points in total (Fig. 3). An autonomous flight plan was created using the software SenseFly. While setting $60 \%$ overlap along line and $70 \%$ overlap between lines, flight height about $110 \sim 120 \mathrm{~m}$ and a flight time below $20 \mathrm{~min}$, optimized the resolution of imagery with respect to battery life. The collected raw data was stored in the sim card integrated in the UAV which was convenient for transferring to the computer. Using these settings, the total flight time was approximately 50 min to collected topographic information data for a 60 hectares study site.

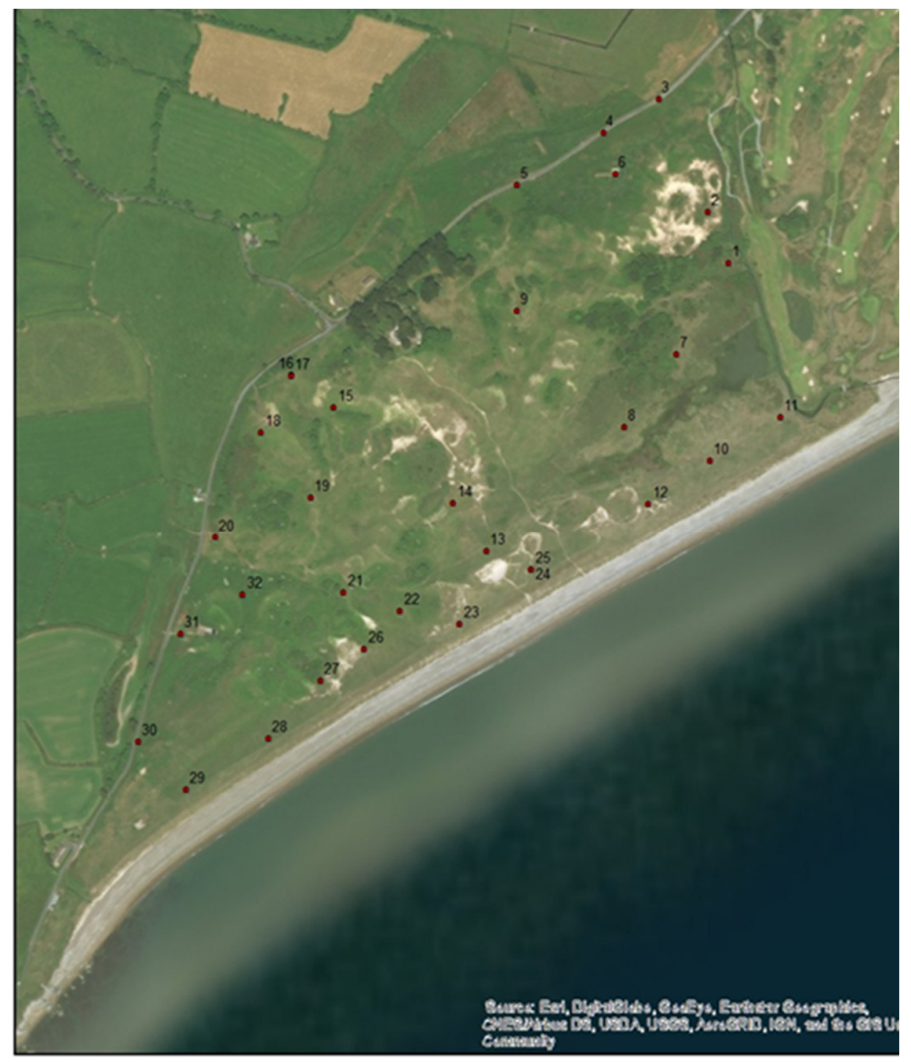

Fig. 3. Ground control points map for UAV surveying

\section{Result}

\section{Flight plan and data collection}

The SenseFly software provides a solution for flight path design for UAV surveying projects. SenseFly has a simple work interface and allow users to get started easily. Based on a given online map, parameters including overlapping of photos, waypoints, flight path, and altitude can be set up. Once set, a prediction of photo numbers and image resolution is presented and the parameters can be revised according to the requirements of the project. After setting, there are many other things that need to be checked before launching the UAV. These include weather conditions, backup battery, SIM card for image storage and UAV controller, to ensure a safe and effectively flight. In this research, the flight plan was selected, with a particular flight grid pattern (Fig. 4) and with a set flight height, and was uploaded to the UAV which was then launched. Before the UAV recorded the image at each waypoint (white points in Fig. 4), it was designed to momentarily level itself. This design aids the stability and quality of the captured images. The flight can be stopped manually with a button on the control screen in case of an emergency. In this research, as the area of 
the study site was large, the area was divided into three sections, as north, centre and south section. In these sections, the number of images collected by the UAV flight was 212, 209, and 149 for north, centre and south section respectively.

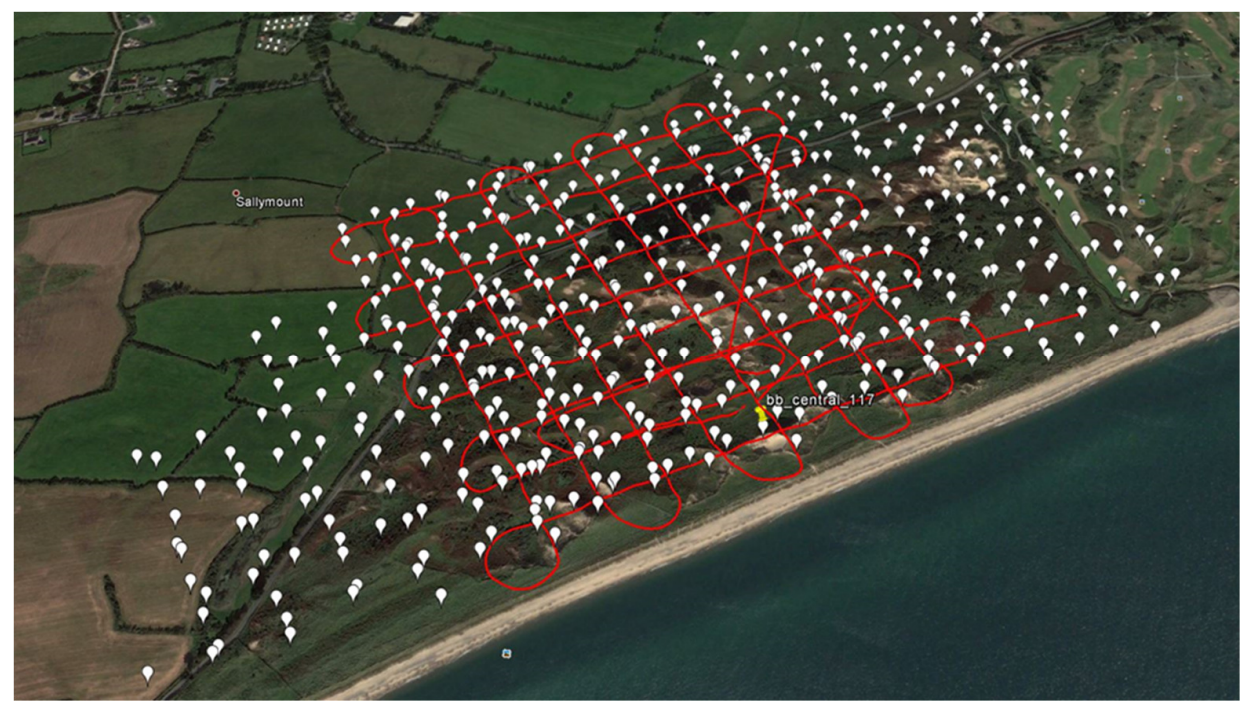

Fig. 4. Flight path for UAV surveying at three sections of study site

\section{Data processing}

Overlapping imagery data processing with SfM software, like Agisoft Photoscan or Pix4D Postflight Terra can generate geo-referenced orthomosaics, DSMs, contour lines, 3-D point clouds and textured mesh models in various formats. As the image database of this research was very large, it was necessary to use a powerful computer with enough storage to save the files. For this research, Pix4D Postflight Terra was selected to process the imagery collected by the UAV. The processing procedure is not complicated but required over 10 hours for each section. First, the images in each section were selected and uploaded. The uploaded images are used to generate a model in a default coordinate system such as WGS84. However, the objective of this research was to construct the model in the ITM coordinate system. For the purpose of transforming the coordinate system, the file containing ground control points with $\mathrm{x}, \mathrm{y}, \mathrm{z}$ information was imported into the project. In order to set an accurate coordinate system for the whole project, at least three ground control point were required to be marked in the uploaded images and each control point should be marked at least two images as in Figure 5.

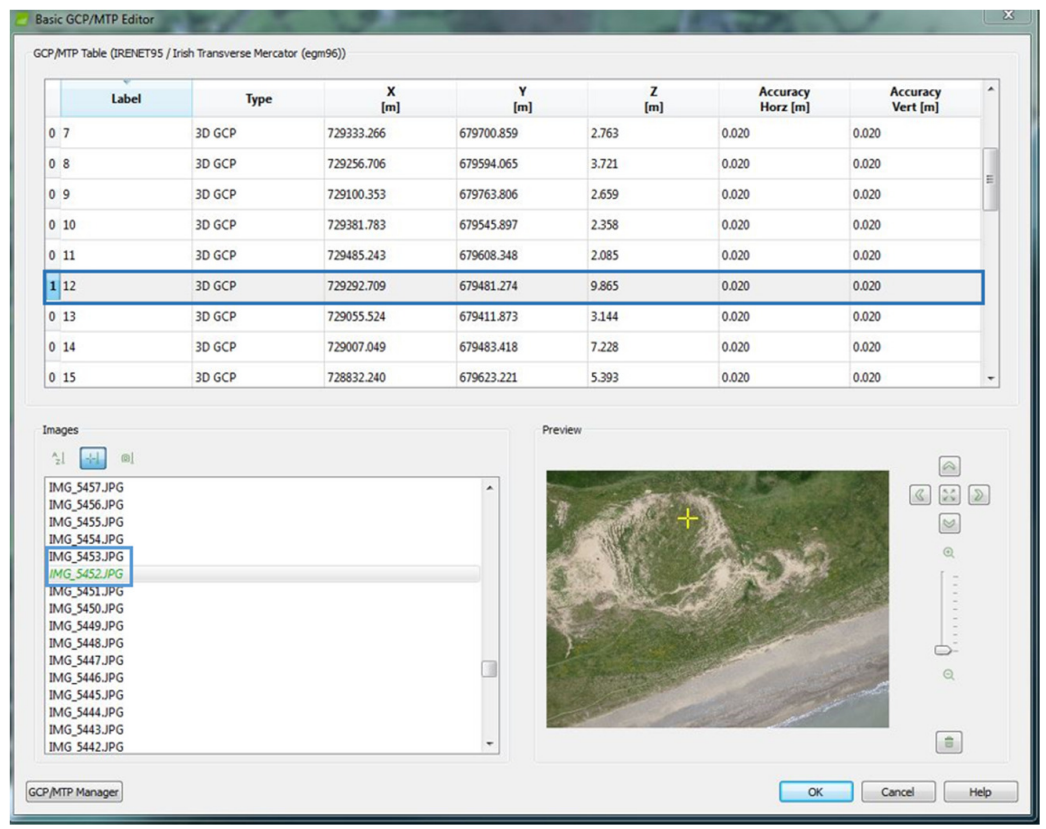

Fig. 5. Ground Control points manager for data processing 
After manually marking three control points in six images, the following step was to customize the processing option for Initial Processing, Point Cloud and Mesh, DSM, Orthomosaic and Index and Resources and Notification (Siebert, Teizer 2014). The main purpose at this stage was to choose the proper scale and format for the resulting data. Pix4D generated a quality assessment report for each processing step. The software first generated the 3D points clouds and then, based on those, the mosaic model and DEM were created. 3D points clouds of the study site contain the coordinate position information in Northing, Easting and Elevation format stored in field 1, field 2 and field 3 respectively (Fig. 6). Figure 7 represents the mosaic model of the study site with a high resolution for vegetation identification. The oblique view of the DEM in Figure 8 gives a perspective representation of the dune complex distribution at the Brittas-Buckroney area. The final result, processed by Pix4D, was a DEM of the study site in the Irish Transverse Mercator coordinate system, with the high resolution about $0.125 \mathrm{~m}$ and Root-Mean-Square (RMS) error $0.050 \mathrm{~m}$. All the results can be accessed by ArcGIS and projected for further analysis.

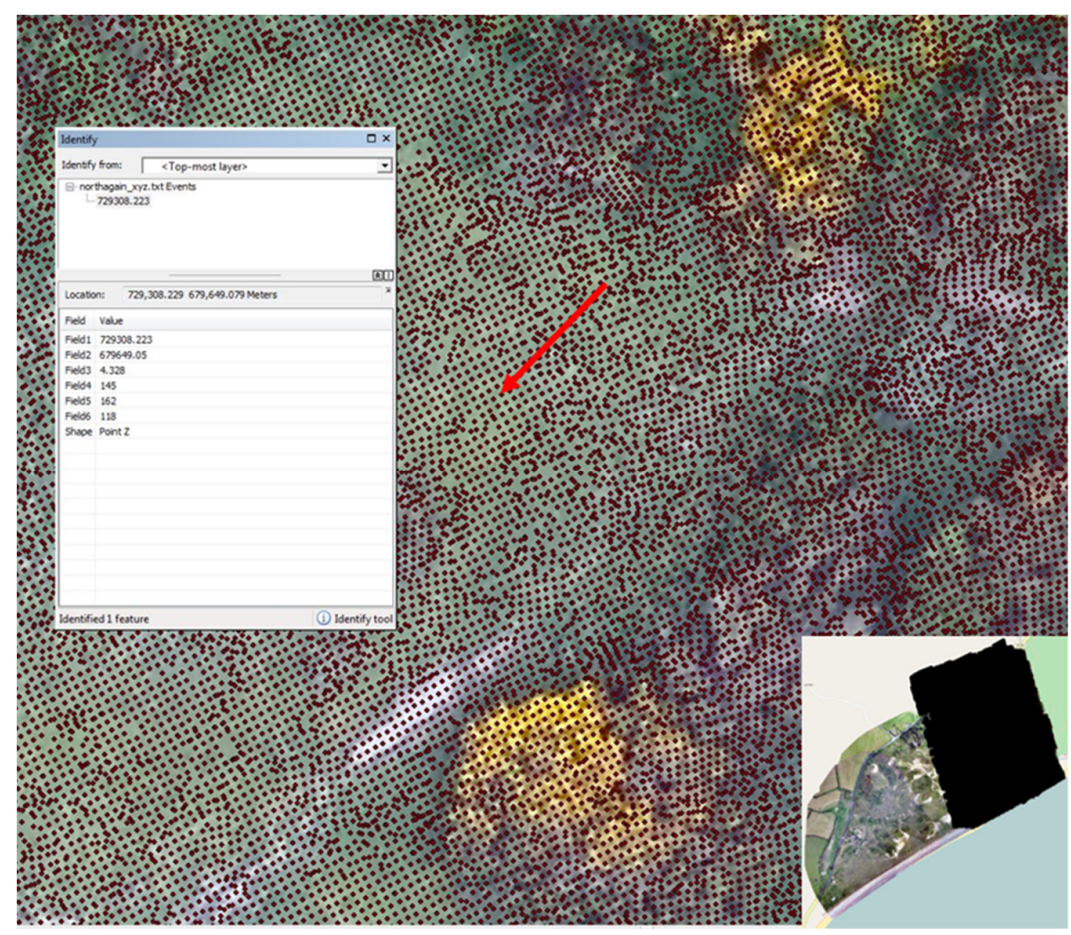

Fig. 6. 3D point clouds for north section of study site

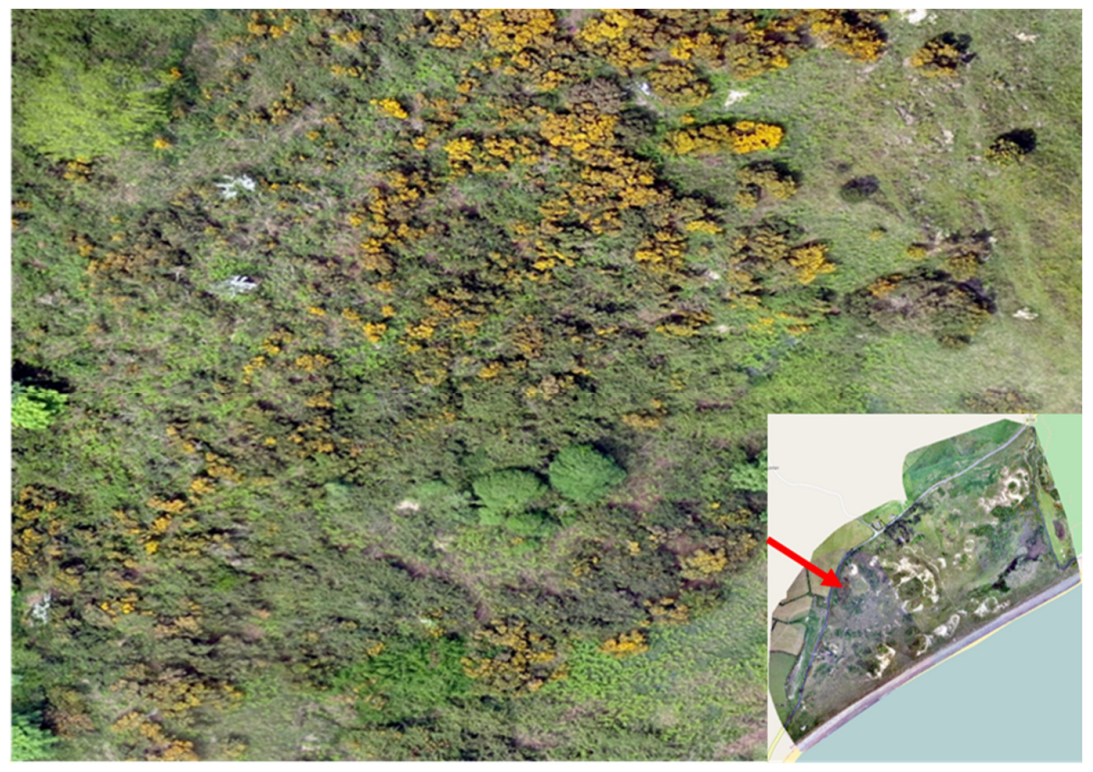

Fig. 7. Mosaic model with high resolution for the study site 


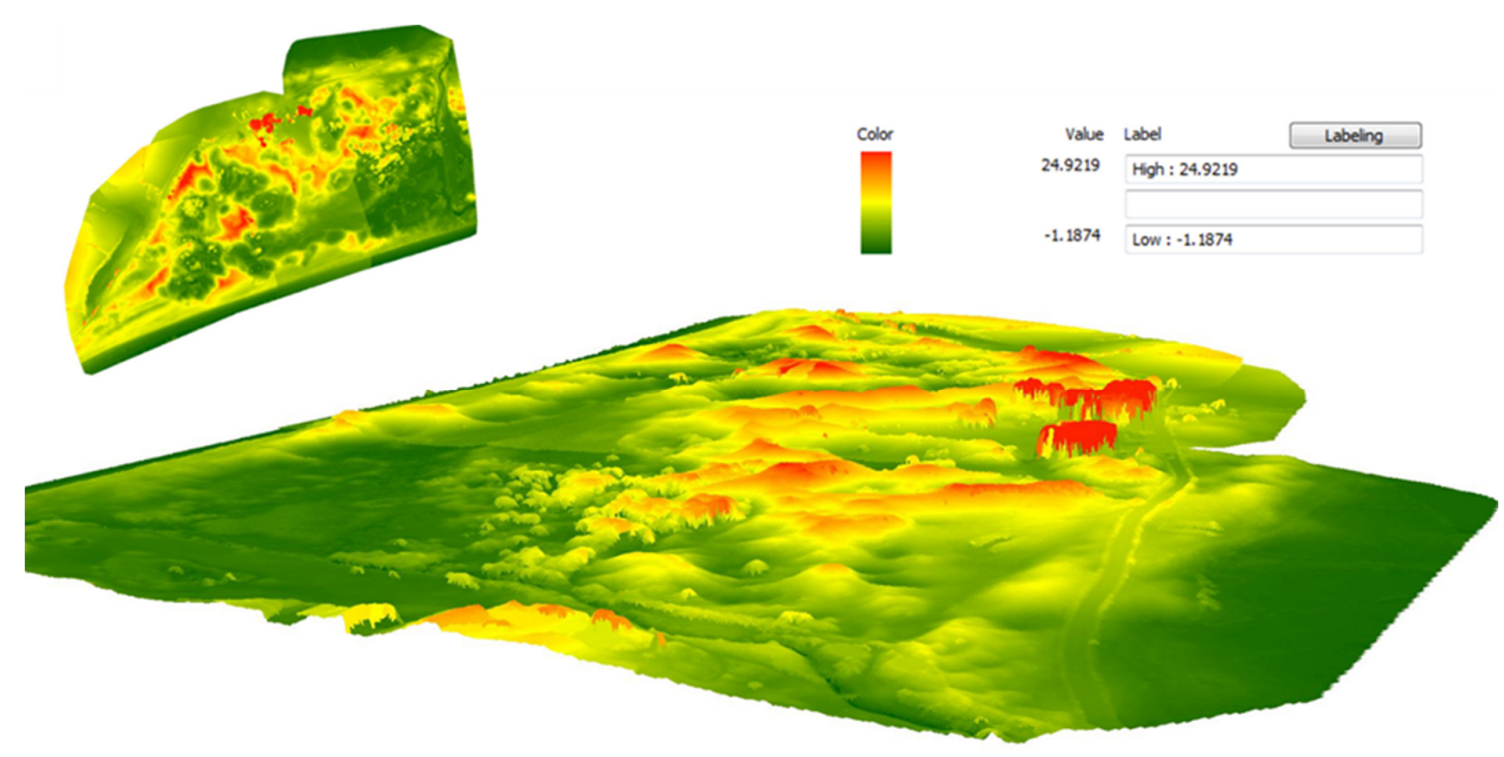

Fig. 8. DEM of the study site

\section{Conclusions}

UAV technology is now well-developed for mapping applications with various UAV equipment, powerful data processing software and efficient data analysis tools (Colomina, Molina 2014). It provides a new option for on-site surveying, significantly reducing the hazard and workload for the construction of topographic maps and building DEM's of a study area. The purpose of this research was to construct the mosaic model and generate a DEM for BrittasBuckroney by using UAV technology. This technique results in images captured from a much wider range of perspectives, better resolution and accuracy, enabling the calculation of the 3-D point cloud position by SfM, generating the mosaic model and DEM (Gonçalves, Henriques 2015).

This research illustrated the benefits and advantages of UAV technology as well as its shortcomings and immaturity as a mapping application for coastal dune areas (Hodgson et al. 2013). In the data collection stage, a fixed wing drone was used to collect images over 60 hectares in one day with a spatial resolution within $0.125 \mathrm{~m}$. This demonstrated the efficiency of the UAV survey method in dune complex areas. As the UAV surveyed remotely, it eased the difficulties of walking through dunes with deep slopes and dense grasses. In addition, functional vegetation distribution and elevation changes all over the dune complex at Brittas-Buckroney area were represented clearly in the mosaic model and in the DEM. A number of other digital surface models could be created through the resulting data format as 3D point clouds (Casella et al. 2014). However, notwithstanding the many benefits and advantages of UAV technology in mapping, it still has some challenges with dune complex surveying. The most obvious weakness is the lack of full details of dunes with steep slopes as the camera is normally configured to capture images in the near vertical. Although the use of UAV's can save a lot of time at the on-site data collecting stage, a considerable amount of time is required for preliminary items such as arranging permits to fly and in training under UAV regulation from IAA. Furthermore, with a high resolution specification and a large study site, the data processing will take considerable time as well. Compared to other conventional survey methods, UAV is less robust as it is limited by weather factors, like wind, rain, low light. As different countries have different legislation controlling UAV use, it is recommended to check and have a good knowledge about the significant use limitations of UAV before the start of the project.

\section{Acknowledgements}

This work funded by Fiosraigh scholarship programme in Dublin Institute Technology. The authors wish to acknowledge Ronan Hogan and Ray Tighe for assistance in data collection in the filed work; SLR Global Environmental Solution Company for providing fixed wing drone eBee for data collection.

\section{Disclosure statement}

Copyright of this paper is the property of Dublin Institute Technology and its content may not be copied or emailed to multiple sites or posted to a listserv without the copyright holder's express written permission. However, users may print, download, or email articles for individual use. 


\section{References}

Bemis, S. P.; Micklethwaite, S.; Turner, D.; James, M. R.; Akciz, S.; Thiele, S. T.; Ali, H. 2014. Ground-based and UAV-based photogrammetry: a multi-scale, high- resolution mapping tool for structural geology and paleoseismology, Journal of Structural Geology 69: 163-178. https://doi.org/10.1016/j.jsg.2014.10.007

Colomina, I.; Molina, P. 2014. Unmanned aerial systems for photogrammetry and remote sensing: a review, ISPRS Journal of Photogrammetry and Remote Sensing 92: 79-97. https://doi.org/10.1016/j.isprsjprs.2014.02.013

Casella, E.; Rovere, A.; Pedroncini, A.; Mucerino, L.; Casella, M.; Alberto, L.; Firpo, M. 2014. Study of wave runup using numerical models and low-altitude aerial photogrammetry: a tool for coastal management, Estuarine, Coastal and Shelf Science 149: 160-167. https://doi.org/10.1016/j.ecss.2014.08.012

Gonçalves, J. A.; Henriques, R. 2015. UAV photogrammetry for topographic monitoring of coastal areas, ISPRS Journal of Photogrammetry and Remote Sensing 104: 101-111. https://doi.org/10.1016/j.isprsjprs.2015.02.009

Hodgson, A.; Kelly, N.; Peel, D. 2013. Unmanned Aerial Vehicles ( UAVs ) for surveying marine fauna: a Dugong case study, PLOS ONE 8(11): e79556. https://doi.org/10.1371/journal.pone.0079556

Lowe, D. G. 1999. Object recognition from local scale-invariant features, in Proc. International Conference on Computer Vision 1999, Kerkyra, Greece, 2: 1150-1157. https://doi.org/10.1109/ICCV.1999.790410

Smith, M. J.; Chandler, J.; Rose, J. 2009. High spatial resolution data acquisition for the geosciences: kite aerial photography, Earth Surface Processes and Landforms 34(1): 155-161. https://dx.doi.org/10.1002/esp.1702

Siebert, S.; Teizer, J. 2014. Automation in Construction Mobile 3D mapping for surveying earthwork projects using an Unmanned Aerial Vehicle (UAV) system, Automation in Construction 41: 1-14. https://doi.org/10.1016/j.autcon.2014.01.004

Tonkin, T. N.; Midgley, N. G. 2016. Ground-control networks for image based surface reconstruction: an investigation of optimum survey designs using UAV derived imagery and structure-from-motion photogrammetry, Remote Sensing 8(9): 786. https://doi.org/10.3390/rs8090786

Turner, I. L.; Harley, M. D.; Drummond, C. D. 2016. UAVs for coastal surveying, Coastal Engineering 114: 19-24. https://doi.org/10.1016/j.coastaleng.2016.03.011

Uysal, M.; Toprak, A. S.; Polat, N. 2015. DEM generation with UAV Photogrammetry and accuracy analysis in Sahitler hill, Measurement 73: 539-543. https://doi.org/10.1016/j.measurement.2015.06.010

Zelizn, V. 2016. Use of low-cost UAV photogrammetry to analyze the accuracy of a digital elevation model in a case study, Measurement 91: 276-287. https://doi.org/10.1016/j.measurement.2016.05.028 